\title{
Integrasi interkoneksi sains dan studi agama dalam implementasi open access repository di Perguruan Tinggi Keagamaan Islam Negeri (PTKIN)
}

\author{
Kardi \\ Pustakawan Madya IAIN Ponorogo \\ email: kardi@iainponorogo.ac.id
}

\begin{abstract}
This study discusses the commitment of leaders of State Islamic Religious Colleges (PTKIN) in supporting the Open Access Repository (OAR) Movement. At present the application of the open access repository at PTKIN has not entirely shown encouraging results, because there are still many institutional repositories of PTKIN who have not yet carried out dissemination of research results, scientific works, theses, theses and dissertations in full (full text) for various reasons. This issue demands the commitment of the leadership of PTKIN, because if the infrastructure (internet network library, installation of applications to upload scientific publications) and human resources (HR) of IT personnel are ready, then just waiting for the realization of the leadership's commitment to support the open access repository movement. The principle in disseminating knowledge is part of religious instruction as a means of da'wah, so that the leadership commitment in providing support to the OAR movement is part of the prophetic paradigm. The purpose of the open access repository $(O A R)$ movement is not only as a means to save scientific work files, but can be a tool to control subsequent scientific publications so that there is no repetition, duplication and plagiarism. Then it could also be a means to overcome the lack of a budget for reasons not to publish books. The author uses a descriptive analysis approach using data collection techniques published on the internet. The object of this research is the chancellor's decision related to the development of institutional repositories as a form of policy commitment that will oversee the implementation of OAR. The purpose of this study is to provide a discourse on the solution of the equal access movement in overcoming information gaps in the PTKIN environment in the context of Islamic symbols to build Islamic civilization in accordance with the ideals of the Unitary Republic of Indonesia.
\end{abstract}

Keywords: Open access; Library; PTKIN; Institutional Repositories; Prophetic

\begin{abstract}
ABSTRAK
Penelitian ini membahas tentang komitmen pimpinan peguruan tinggi keagamaan Islam Negeri (PTKIN) dalam mendukung Gerakan Open Access Repository (OAR). Saat ini penerapan open access repository di PTKIN belum seluruhnya menunjukkan hasil yang menggembirakan, soalnya masih banyak institutional repository PTKIN yang belum menjalankan diseminasi hasil penelitian, karya ilmiah, skripsi, tesis, dan disertasi secara utuh (fulltext) karena berbagai alasan. Permasalahan ini menuntut komitmen Pimpinan PTKIN, karena jika infrastruktur (perpustakaan jaringan internet, instalasi aplikasi untuk mengunggah publikasi ilmiah) dan sumber daya manusia (SDM) tenaga TI sudah siap maka tinggal menunggu realisasi komitmen pimpinan untuk mendukung gerakan open access repository tersebut. Prinsip dalam menyebarluaskan ilmu pengetahuan adalah merupakan
\end{abstract}


sebagian perintah agama sebagai sarana dakwah, sehingga komitmen pimpinan dalam memberikan dukungan terhadap gerakan OAR adalah merupakan bagian dari paradigma profetik. Tujuan dari gerakan open access repository (OAR) ini bukan sekedar sebagai sarana untuk menyimpan file-file karya ilmiah akan tetapi bisa sebagai alat kontrol publikasi ilmiah berikutnya agar tidak ada repetisi, duplikasi dan plagiasi. Kemudian bisa juga sebagai sarana untuk mengatasi minimnya anggaran karena alasan tidak dana menerbitkan buku. Penulis menggunakan pendekatan analisis deskriptif dengan menggunakan teknik pengumpulan data yang dipublikasikan di internet. Objek penelitian ini adalah surat keputusan rektor terkait dalam pengembangan institutional repository sebagai bentuk komitmen kebijakan yang akan memayungi implementasi OAR. Tujuan dari penelitian ini adalah memberikan wacana terhadap solusi gerakan akses sama rata dalam mengatasi kesenjangan informasi di lingkungan PTKIN dalam rangka syiar Islam membangun peradaban Islam sesuai cita-cita Negara Kesatuan Republik Indonesia.

Kata Kunci : Open access; Perpustakaan; PTKIN; Repositori Institusi; Profetik

\section{A. Pendahuluan}

Peran penting perpustakaan perguruan tinggi dalam pengembangan institutional repository memberikan kontribusi secara langsung terhadap pemeringkatan Web of Universities atau Webometrics. Hal ini merupakan poin tambahan bagi pengembang IR dalam pengembangan publikasi ilmiah.(Tjiek 2011, 177) Komitmen perguruan tinggi dalam mendukung gerakan Open Access Repository memberikan kontribusi pada Peringkat Web of Repositories. Melalui penilaian webometrik bisa mengukur sejauh mana tingkat komitmen tersebut mampu mendorong perguruan tinggi untuk bersedia memgunggah seluruh hasil riset (baik yang published dan unpublished) kepada masyarakat luas secara penuh (lengkap seluruh kontennya) melalui satu aplikasi yang dikenal dengan istilah repository bisa menggunakan platform eprints, ganecha digital library (GDL), omeka, senayan library information management systems (Slims) juga bisa atau yang lainnya.("Ranking Web of Repositories Perguruan Tinggi Keagamaan Islam Negeri (PTKIN) - Sharing Is Caring" n.d.)

Pengembangan repositori institusi menjadi tren pengembangan perpustakaan perguruan tinggi. Hal ini menunjukkan perkembangan inovasi yang sangat dinamis. Banyak perguruan tinggi mulai sibuk mengembangkan perpustakaan digital dengan membangun penyimpanan koleksi digital berupa aplikasi penyimpanan koleksi arsip dan yang merupakan kekayaan intelektual lokal perguruan tinggi yang bersangkutan. Pada akhirnya dikenal dengan istilah repositori institusi (Institutional Repository/IR). PTKIN di Indonesia ada 58 perguruan tinggi namun dari jumlah itu belum semuanya memiliki IR yang bisa diakses secara terbuka. Padahal pengelolaan IR ini diharapkan dapat diakses seluas-luas secara terbuka, dengan demikian bisa meringankan biaya pengadaan koleksi dan mempermudah pemustaka dalam memperoleh informasi koleksi secara mudah, murah dan cepat.

Namun harapan tadi belum sepenuhnya terwujud karena tidak sedikit IR di perpustakaan PTKIN masih belum memberikan layanan sesuai misi awal IR itu dibangun. IR dibangun untuk memberikan akses yang seluas-luasnya secara terbuka atau yang saat ini sering dikenal dengan istilah open access. Implementasi open access repository (OAR) di PTKIN masih terkesan setengah hati karena masih ada perpustakaan yang mengembangkan IR tapi belum mengunggah konten ilmiah secara utuh (fulltext), hanya mengunggah beberapa bab secara terpisah. Berbagai permasalahan yang dihadapi pengelola IR. Hal ini 
masih belum seiring sejalan dengan semangat gerakan open access. Faktor-faktor penghambat IR biasanya adalah faktor kebijakan pimpinan disamping permasalahanpermasalahan seperti masalah anggaran, sumber daya manusia (SDM), infrastruktur atau sarana prasarana. Peran komitmen pimpinan PTKIN dalam kebijakan untuk membuka akses secara terbuka (open access) sangat menentukan efektifitas repositori. Kebijakan tentang OAR yang menerapkan information sharing secara utuh atau full text seperti skripsi, tesis, disertasi dan karya ilmiah lainnya sering bergantung pada kebijakan pimpinan. Setidaknya ada surat keputusan pimpinan yang memberikan payung hukum pengembangan repositori institusi untuk menentukan format akses selanjutnya.

Kebijakan pimpinan dalam membuka akses publikasi ilmiah secara utuh (fulltext) adalah seperti kebijakan mewajibkan jurnal tercetak untuk beralih ke jurnal online ${ }^{1}$ merupakan salah satu contoh bentuk komitmen pimpinan dalam membuka akses secara open access dengan total fulltext, dengan kriteria-kriteria keterbukaan (openess), kekayaan informasi (richment) masuk dalam kriteria penilaian akreditasi jurnal online.(Iswara 2016, 3) Kriteria tersebut bisa menjadi ancangan pengambil kebijakan bahwa mengunggah hasil riset secara online itu belum cukup karena harus memenuhi kriteria lain dalam meningkatkan mutu riset dengan memperhatikan kriteria impact factor dan sustainability kegiatan unggah hasil riset. Sehingga membangun repositori tidak hanya sekedar ada namun perlu ada quality control agar memberi kontribusi dalam peningkatan mutu riset.

Satu contoh adalah penelitian sebelumnya yang membahas tentang aspek kesiapan lembaga perpustakaan perguruan tinggi dalam mengimplementasikan open access repository sebagaimana dibahas Ida Fajar Prianto dalam disertasinya yang berjudul Readiness of Indonesian academic libraries for open access and open access repositories implementation: A study on Indonesian open access repositories registered in OpenDOAR.(Priyanto 2015) Kemudian dari sisi kesiapan infrastruktur, dosen, mahasiswa juga pernah dibahas oleh Toong Tjiek Liauw (Aditya Nugraha dari Universitas Petra Surabaya) dalam sebuah artikel yang bertajuk Institutional Repositories and Open Access in the Indonesian Higher Education Sector.(Liauw 2017) Namun dalam penelitian tersebut belum ada pendekatan studi agama untuk melengkapi hasil riset tersebut. Demikian pula selanjutnya sebuah penelitian harus berkelanjutan.

Paparan di atas ada satu aspek dalam pengembangan OAR yang sangat urgen dan belum tersentuh yaitu komitmen pimpinan perguruan tinggi dalam mewujudkan makna open access yang sebenarnya dalam berbagi informasi secara utuh (fulltext). Permasalahan tersebut menjadi fokus kajian penelitian ini. Mengapa komitmen pimpinan menjadi penting untuk diteliti karena fakta di lapangan seringkali pengelola IR tidak berani membuka akses secara utuh (fulltext) karena belum ada payung hukum dan aspek lain yang memberikan dukungan sistem untuk membuat open access repository. Padahal inti dari OAR itu adalah keterbukaan akses informasi.

Tujuan dari penelitian ini adalah ingin menakar komitmen dan pemahaman pimpinan dalam mendukung implementasi OAR. Ukuran komitemen tersebut berupa penerbitan surat keputusan pimpinan dalam kebijakan pengemanagn IR. Sejatinya pemikiran yang sangat mendasar dari penelitian ini adalah dalam kerangka syiar dakwah Islam dengan semangat menerapan institutional repository secara open access. Sebagai salah satu bentuk syiar Islam

1 Regulasi yang mengatur publikasi karya ilmiah sebagaimana Surat Edaran DIKTI Nomor 1223/E/T/2012 tertangal 27 September 2012 perihal Kewajiban Penerbitan Terbitan Berkala Ilimah secara Elektronik dan Surat Edaran DIKTI Nomor 193/E/SE/2015 tertanggal 10 Desember 2015 perihal Akreditasi Jurnal Ilmiah Secara Elektronik, maka perguruan tinggi minimal menyediakan wadah untuk semua terbitan ilmiah yang diterbitkan di lingkungan perguruan tinggi agar dapat memenuhi persyaratan sesuai dengan surat edaran tersebut dan mempublikasikan dalam jurnal yang terbit secara elektronik/daring. 
dengan cara mengelola informasi karya ilmiah untuk kemudian didistribusikan secara terbuka dalam rangka membangun peradaban manusia sesuai cita-cita Negara Kesatuan Republik Indonesia (NKRI). Sehingga tidak ada lagi yang menyembunyikan informasi atau mengurangi volume informasi dengan maksud tertentu secara sepihak. Hal ini menjadi aneh lagi jika ada hasil penelitian yang dibiayai pemerintah tapi produknya tidak bisa diakses oleh masyarakat secara terbuka (open access).

Penelitian ini menggunakan pendekatan deskriptif dalam memaparkan penulisan hasil penelitian. Dengan demikian agar pembahasan ini tidak bias maka artikel ini dibatasi pada komitmen pimpinan lembaga perguruan tinggi keagamaan Islam negeri (PTKIN).

\section{B. Paradigma Profetik}

\section{Pengertian Paradigma Profetik}

Sejarah perkembangan ilmu pengetahuan menunjukkan adanya dimensi keilmuan yang semakin berkembang dan saling berinteraksi, hal ini seiring dengan perkembangan teknologi informasi yang kian pesat dalam menyebarluaskan hasil-hasil penelitian. Terutama dalam perkembangan studi ilmu perpustakaan dan informasi, bisa ditemukan beberapa tulisan dari artikel yang diterbitkan oleh jurnal-jurnal kajian ilmu informasi dan perpustakaan, seperti adanya artikel yang terbit di jurnal Al-Maktabah UIN Syarif Hidayatullah,(Rifaudin 2017, 46-62) dan jurnal Pustakaloka IAIN Ponorogo yang mencoba membahas tentang paradigma profetik terkait kepemimpinan profetik.(Anwar 2017, 69-92) Ini artinya konsep perkembangan ilmu tentang paradigma profetik juga sudah mulai merambah masuk dalam kajian ilmu informasi dan perpustakaan sebagai bagian dari kajian filosofis keilmuaan secara mendasar. Bagaimana internalisasi paradigma profetik tersebut masuk dalam kajian ilmu perpustakaan dan informasi, dari sini penelitian ini akan dimulai berdasarkan temuan-temuan artikel tentang profetik yang sudah pernah terbit di beberapa jurnal kajian informasi dan perpustakaan tersebut.

Kata profetik berasal dari bahasa Inggris 'prophet' yang berarti nabi. Oxford Dictionary memberikan arti 'prophetic' ...of, pertaining or proper to a prophet or prophecy"; ...characterized by, containing, or of the nature of prophecy, predictive”. Sehingga profetik mempunyai arti adalah kenabian. Benih-benih pemikiran ini sebenarnya awalnya ditabur oleh Kuntowijoyo dalam bukunya Paradigma Islam:interpretasi untuk aksi.(Ahimsa-Putra 2016,2) Di mana sifat-sifat kenabian mampu menginspirasi sifat peminpin yang ideal.

Islam memberikan gambaran sifat ideal pemimpin sebagaimana ditulis Aunur Rohim dan Iip Wijayanto bahwa seorang pemimpin harus mampu memimpin dan mengendalikan dirinya sebelum memimpin orang lain. Kemudian memiliki kemampuan manajerial yang baik karena seorang pemimpin itu harus dipilih dari kualitas yang memiliki konsep relasi yang mampu menjembatani berbagai perbedaan yang ada di tengah-tangah masyarakatnya. Disamping itu seorang pemimpin harus memiliki visi Al-Quran dan misinya menegakkan kebenaran. Lalu memiliki sikap tawadhu dan mawas diri dalam mengemban amanah Allah, karena pada prinsipnya kepemimpinan itu bukan saja harus dipertanggungjawabkan di hadapan Allah SWT. Dan yang paling menarik adalah pemimpin yang memiliki sifat sidiq (benar), amanah (terpercaya), tabligh (menyampaikan apa adanya), fathonah (pandai) serta menyadari sepenuhnya bahwa Allah memberikan kemampuan yang berbeda-beda bagi setiap orang serta menerimanya dengan rasa syukur dan ikhlas. 


\section{Komitmen Pimpinan}

Komitmen pimpinan secara organisasional dipandang sebagai suatu orientasi nilai terhadap organisasi yang menunjukkan individu yang sangat memikirkan dan mengutamakan pekerjaan dan organisasinya. Individu akan berusaha memberikan segala usaha yang dimilikinya dalam rangka membantu organisasi mencapai tujuannya. Komitmen organisasi didefinisikan sebagai "The degree to which an employee identifies with a particular organization and its goals, and wishes to maintain membership in the organization".("Robbins, P. Stephen, 2003. Perilaku Organisasi: Konsep, Kontroversi, Dan Aplikasi. Alih Bahasa Handayana Pujaatmika. Edisi Bahasa Indonesia. Jakarta: Prenhalindo. Penelusuran Google" n.d.) Diana Sulianti K.L.Tobing(Tobing 2009, 32) mengutip keterangan Porter et al.(Porter and Steers 1973) yang memberikan pengertian komitmen organisasional sebagai kekuatan individu dalam suatu organisasi dan keterlibatan dalam organisasi tertentu, yang dicirikan oleh tiga elemen psikologis, pertama, keinginan kuat menjadi anggota organisasi tertentu; kedua, kemauan untuk berupaya semaksimal mungkin demi organisasi; ketiga, keyakinan pasti dan pemahaman terhadap nilai-nilai dan tujuan organisasi. Allen and Meyer(Allen and Meyer 1990) memberikan tiga komitmen organisasi yaitu pertama, komitmen afektif adalah keterikatan emosional, identifikasi dan keterlibatan dalam suatu organisasi. Kedua, komitmen kontinuan maksudnya komitmen individu yang didasarkan pada pertimbangan tentang apa yang harus dikorbankan bila akan meninggalkan organisasi. Ketiga, komitmen normatif atau keyakinan individu tentang tanggung jawab terhadap organisasi. Individu tetap tinggal pada suatu organisasi karena merasa wajib untuk loyal pada organisasi tersebut. Hal yang umum dari ketiga pendekatan tersebut adalah pandangan bahwa komitmen merupakan kondisi psikologis yang mencirikan hubungan antara karyawan dengan organisasi dan memiliki implikasi bagi keputusan individu untuk tetap berada atau meninggalkan organisasi.

Namun demikian sifat dari kondisi psikologis untuk tiap bentuk komitmen sangat berbeda. Karyawan dengan komitmen afektif yang kuat sehingga akan tetap berada dalam organisasi karena menginginkannya. Kemudian karyawan dengan komitmen kontinuan yang kuat tetap berada dalam organisasi karena membutuhkannya, sedangkan karyawan yang memiliki komitmen normatif kuat tetap maka akan berada dalam organisasi karena mereka harus melakukan.

\section{Teori tentang Kepemimpinan}

Unsur utama untuk meraih sukses gemilang dalam suatu organisasi adalah kepemimpinan. Untuk mengetahui arti kepemimpinan perlu tahu makna dari pemimpin (leader) lebih dahulu. Kepemimpinan dilakukan seorang pemimpin yang memikul beban tugas dengan beraktivitas untuk melaksanakan kepemimpinan tersebut. Pemimpin adalah seorang yang diharapkan mempunyai kemampuan untuk mempengaruhi, memberi petunjuk dan juga mampu menentukan individu untuk mencapai tujuan organisasi.(Stueart and Moran 2007, 352) Maka pemimpin adalah aktor perubahan melalui kegiatan dalam rangka mempengaruhi orang-orang lebih dari pengaruh orang-orang tersebut kepada dirinya.(Spillane 2005, 10) Kedua definisi di atas sama-sama pada satu kata definisi pengaruh mempengaruhi. Kata kunci untuk kepemimpinan adalah "pengaruh" bukan "kekuasaan".

Mengutip artikel Kahar yang berjudul konsep kepemimpinan dalam perubahan organisasi (orgnizational change) dalam perguruan tinggi menyimpulkan bahwa rencana dan implementasi perubahan organisasi diperlukan pemimpin yang kuat untuk melakukan tindakan pimpinan agar mempengaruhi, mengarahkan anggota untuk mencapai tujuan. Berdasarkan teori tindakan tersebut dalam aspek-aspek kepemimpinan sebagai pemimpin yang memiliki visi (visioner), komunikator, agen perubahan (change agent), pelatih (coach) dan evaluator pemanfaatan teknologi informasi.(Kahar 2008, 27) 


\section{Teori tentang open access repository $(\mathrm{OAR})$}

Open access adalah "... a term used to describe a radical new dissemination model for scientific research publications. Open Access is gradually replacing the earlier method of selling journal subscriptions and restricting access to paying readers only, a model that matured and established itself during the era of printed journals".(Björk et al. 2014a, 3) Maksudnya, bahwa Open Access (OA) adalah istilah yang digunakan untuk menggambarkan model diseminasi baru yang radikal untuk publikasi penelitian ilmiah. Open Access secara bertahap menggantikan metode sebelumnya yang menjual langganan jurnal dan membatasi akses ke pembaca berbayar saja, sebuah model yang matang dan mapan pada era jurnal cetak.

Open Access (OA) adalah akses gratis yang tidak terbatas ke versi elektronik publikasi ilmiah. Untuk artikel jurnal peer review ada dua main rute ke OA, menerbitkan jurnal OA (Gold OA) atau pengarsipan salinan artikel atau manuskrip di lokasi web lain (Green OA). Penelitian ini berfokus pada meringkas dan memperluas pengetahuan terkini tentang Green $O A$. Sebuah sintesis penelitian sebelumnya menunjukkan bahwa cakupan Green OA dari semua artikel jurnal yang diterbitkan sekitar $12 \%$, dengan disiplin substansial variasi. Biasanya, salinan Green $O A$ tersedia dengan cukup banyak waktu penundaan, sebagian disebabkan oleh penerbit yang memberlakukan masa embargo, dan sebagian lagi oleh kecenderungan penulis untuk mengarsipkan manuskrip hanya secara berkala. Meski Green $O A$ salinan idealnya harus diarsipkan di repositori yang tepat, sebagian besar disimpan di halaman rumah dan lokasi serupa, tanpa jaminan jangka panjang kelestarian. Seringkali lokasi tersebut berisi salinan artikel yang dipublikasikan secara pasti, yang mungkin melanggar hak eksklusif penerbit. Dasar teknisnya untuk mengunggah Green OA menjadi semakin padat, yang sebagian besar disebabkan oleh peningkatan pesat jumlah repositori institusional. Jumlah artikel dalam lingkup mandat $\mathrm{OA}$, yang sangat mempengaruhi tingkat selfarchival artikel, masih rendah.(Björk et al. 2014b, 2)

Meskipun dalam sejumlah terbitan tentang topik repositori institusional telah ada dalam beberapa tahun terakhir memberikan definisi yang konkrit, namun repositori institusional (IR) sulit dilakukan. Clifford Lynch (2003), Direktur Eksekutif Coalition for Networked Information, menggambarkan IR sebagai satu set layanan yang ditawarkan universitas kepada anggota komunitasnya untuk pengelolaan dan diseminasi bahan digital yang dibuat oleh institusi dan anggota masyarakatnya. Definisi Lynch sangat penting karena layanan bukan teknologi semata. Meski dengan definisi ini pertanyaannya tetap ada, apa tepatnya "rangkaian layanan" yang merujuk Lynch ini. Sayangnya, pertanyaan ini tidak memiliki jawaban tunggal dan benar karena repositori institusional harus didefinisikan secara institusional. Agar sukses, IR harus menyediakan seperangkat layanan yang dibutuhkan dengan keunikan komunitas pengguna, dan layanan ini harus berbeda dari institusi ke institusi.(Gibbons 2009, 6)

\section{Paradigma Profetik Komitmen Pimpinan Dalam Implementasi Open Access Repository Pada Ptkin : Representasi Integrasi Interkoneksi Ilmu Perpustakaan Dan Informasi Dengan Studi Agama}

Pentingnya komitmen pimpinan dalam sebuah perguruan tinggi untuk memahami pentingnya publikasi ilmiah bisa dituangkan dalam sebuah sebuah surat keputusan pimpinan (rektor) tentang repositori institusi. Mengingat fungsi dan peran repositori sebagai etalase karya ilmiah yang telah dihasilkan oleh perguruan tinggi. Menginsyafi bahwa repositori sebagai salah satu cara yang sangat efektif dalam mewujudkan terciptanya komunikasi ilmiah (scholarly communication) yang dinamis. Scholarly communication bukan sebuah istilah baru atau yang baru mewacana dalam dunia library and information science (LIS). 
Meskipun sudah mulai menjadi discourse sejak lama. Istilah scholarly communication bukan berarti sebuah produk, namun sebagai sebuah proses yang iterative atau cyclical, yang dilakukan secara berulang dan terus-menerus seperti sebuah siklus mulai dari merancang, menyebarluaskan (dissemination) dan menyimpannya (preservation) agar mudah diakses oleh khalayak. Proses seperti ini kemudian juga dikenal sebagai scholarly communication cycle.(Harliansyah 2017, 3)

Publikasi ilmiah merupakan sarana untuk menyalurkan komunikasi ilmiah dan apabila terjadi krisis komunikasi ilmiah, maka proses penyebarluasan dan pengembangan ilmu pengetahuan terutama di negara-negara dunia ketiga akan terhambat. Idealnya ilmu pengetahuan itu untuk melayani kemanusiaan menjadi jauh dari kenyataan. Kesejahteraan sosial yang diidamkan bersama menjadi utopia. Gerakan open access merupakan cara agar komunikasi ilmiah semakin meningkat sehingga akan menghasilkan banyak publikasi ilmiah. Gerakan OAR ini menuntut komitmen pemimpin dalam membangun repositori institusi.

Penelitian ini bertujuan menunjukkan bahwa ada integrasi dan interkoneksi kajian informasi dan perpustakaan dengan studi Islam dalam kajian ini. Kata kunci yang menarik untuk diintegrasikan dengan studi keislaman adalah konsep kepemimpinan dalam perspektif paradigma profetik dalam menyebarkan informasi secara terbuka (open access). Dalam studi Islam ada banyak perintah untuk menyebarkan ilmu walaupun satu ayat. Lalu ada juga hadits yang mengatakan untuk tidak menyimpan ilmu atau sering dikenal dengan istilah menyembunyikan ilmu (katmul 'ilmi), sehingga kalau informasi yang disajikan oleh pusat informasi seperti perpustakaan tidak menggunakan sistem layanan open access maka perpustakaan tersebut termasuk katmul 'ilmi. Masih ada hubungannya dengan open access publikasi ilmiah, ada seorang profesor mengatakan bahwa dosen yang tidak mau melakukan publikasi ilmiah maka nanti akan mendapat pertanyaan kubur, apakah ilmunya sudah didiseminasikan atau belum. Hal ini menunjukkan betapa pentingnya diseminasi informasi secara terbuka dalam rangka meningkatkan publikasi ilmiah dan komunikasi ilmiah (scholarly communication).

Hukum menyembunyikan ilmu agama atau informasi sebagaimana dinyatakan dalam firman Allah (QS al-Baqarah 2: 159-160) yang artinya sebagai berikut :

"Sesungguhnya orang-orang yang menyembunyikan apa yang telah Kami turunkan berupa keterangan-keterangan(yang jelas) dan petunjuk, setelah Kami menerangkannya kepada manusia dalam al-Kitab, mereka itu dilakanat; Kecuali mereka yang telah tobat dan mengadakan perbaikan dan menerangkan (kebenaran), maka terhadap mereka itulah Aku menerima tobatnya dan Akulah yang Maha menerima tobat lagi Maha Penyayang.

Adapun yang dimaksud dengan keterangan ayat di atas, yang dimaksud dengan menyembunyikan keterangan dan petunjuk tersebut adalah informasi tentang kenabian Nabi Muhammad saw dan tidak mau memberitakannya karena rasa dengki dan marah. Imam asSayuthi meriwayatkan dalam kitab ad-Durrul Mantsur dari Ibnu Abbas r.a. bahwa Mu'adz bin Jabal dan sebagian sahabat bertanya kepada segolongan Pendeta Yahudi tentang sebagian isi Taurat, kemudian mereka menyembunyikannya dan menolak untuk memberitakannya, kemudian turunlah ayat diatas.

Ayat tersebut adalah tentang ihwal Ahli Kitab dari pendeta-pendeta Yahudi dan Nasrani yang menyembunyikan sifat-sifat Nabi saw sebagaimana disebutkan dalam sebab turunnya ayat ini, tetapi lebih luas ayat ini mengena kepada setiap orang yang menyembunyikan ayat-ayat Allah, yang menyembunyikan hukum-hukum agama, karena 
yang terpakai sebagaimana dikatakan oleh ulama ushul adalah keumumam lafalnya, bukan kekhususan sebabnya. Bahkan pada firman Allah yang lain juga menegaskan bahwa tidak dibenarkan menyembunyikan informasi tentang kebenaran yang perlu diketahui oleh masyarakat luas dan larangan mencampuradukkan kebenaran dan kebathilan.(Q.S. :8:8).(Kahfi 2006, 324)

Penjelasan tersebut diatas tentang perintah untuk membuka akses informasi ilmiah dalam perguruan tinggi setidaknya sudah dipahami oleh pimpinan lembaga dalam hal ini PTKIN. Ada dinamika yang berkembang di kalangan akademisi saat ini adalah tentang kewajiban untuk unggah karya ilmiah pada repositori atau elektronik jurnal sebagai persyaratan kenaikan pangkat. Hal ini yang mendorong peningkatan publikasi ilmiah semakin meningkat. Pada akhirnya repositori institusi sudah menjadi hal penting dalam pengembangan ilmu pengetahuan secara luas. Demikian pula dengan peran perpustakaan dan pustakawan selain mengumpulkan informasi tapi juga mendistribusikannya secara legal karena ada amanah peraturan yang menaunginya berupa surat keputusan pimpinan lembaga perguruan tinggi.

Wujud integrasi interkoneksi dari artikel ini adalah adanya perjumpaan antara sains (kajian tentang ilmu perpustkaan dan informasi) dengan studi agama yang mengamanahkan kepada semua pelaksana pendidikan termasuk diantaranya pustakawan dan pengambil kebijakan agar menyampaikan informasi ilmiah secara terbuka demi tersebarnya pen getahuan agar lebih maju dan berkembang lagi.

\section{Kesimpulan}

Peran pimpinan PTKIN dalam mengembangkan repositori institusi sangat penting dan urgen dalam rangka meningkatkan reputasi perguruan tinggi dalam menyebarluaskan publikasi ilmiah dan meningkatkan budaya komunikasi ilmiah secara terbuka. Komitmen pimpinan PTKIN sangat diperlukan dalam mendukung implementasi open access repository. Bentuk komitmen tersebut berupa surat keputusan yang dapat memayungi gerakan open access repository sehingga dari keputusan tersebut menjadi gerakan bersama. Pimpinan PTKIN yang dimaksud adalah seluruh stakeholder yang memback-up keputusan untuk membuka akses secara utuh sebuah karya ilmiah dengan pemahaman sebagai bentuk syiar Islam dan membangun peradaban dan tradisi keilmuan di Indonesia sesuai cita-cita Negara Kesatuan Republik Indonesia (NKRI) sebagai wujud dari komitmen pimpinan yang profetik. Paradigma profetik mengikuti sifat kenabian yakni tabligh (menyampaikan informasi), amanah (dapat dipercaya dalam menyampaikan informasi), fathonah (penuh tanggung jawab atau komitmen mengawal jalannya program kegiatan), lalu shidiq (jujur dalam menyampaikan informasi tidak ada yang disembunyikan termasuk dalam misi dari gerakan open access repository).

\section{DAFTAR PUSTAKA}

Ahimsa-Putra, Heddy Shri. 2016. Paradigma profetik Islam: epistemologi, etos, dan model. Yogyakarta: Gadjah Mada University Press.

Allen, Natalie J., and John P. Meyer. 1990. "The Measurement and Antecedents of Affective, Continuance and Normative Commitment to the Organization." Journal of Occupational Psychology 63 (1): 1-18.

Anwar, Ahmad. 2017. "Tipe Kepemimpinan Profetik Konsep Dan Implementasinya Dalam Kepemimpinan Di Perpustakaan.” Pustakaloka 9 (1): 69-82. 
Ap, Rachman. "Tafsir Qs. Al Baqarah 2: 159-160-Hukum Menyembunyikan Ilmu Agama.” ONLYQURAN, November 17, 2011.

Björk, Bo-Christer, Mikael Laakso, Patrik Welling, and Patrik Paetau. 2014a. "Anatomy of Green Open Access." Journal of the Association for Information Science and Technology 65 (2): 237-250.

2014b. "Anatomy of Green Open Access." Journal of the Association for Information Science and Technology 65 (2): 237-250.

Gibbons, Susan. 2009. "Defining an Institutional Repository." Library Technology Reports 40 (4): 6-10.

Harliansyah, Faizuddin. 2017. "Scholarly Communication Dan Peran Perpustakaan Perguruan Tinggi." Shaut Al-Maktabah: Jurnal Perpustakaan, Arsip \& Dokumentasi 9 (1): 1-24.

Iswara, Vincentius Widya. 2016. "Pengelolaan Jurnal Online Unika Widya Mandira Mengunakan Open Journal System (OJS)."

Kahar, Irawaty A. 2008. "Konsep Kepemimpinan Dalam Perubahan Organisasi (Organizational Change) Pada Perpustakaan Perguruan Tinggi." Pustaha: Jurnal Studi Perpustakaan Dan Informasi 4 (1).

Kahfi, Agus Sofyandi. 2006. "Informasi Dalam Perspektif Islam." Mediator: Jurnal Komunikasi 7 (2): 321-328.

Liauw, Toong Tjiek. 2017. "Institutional Repositories and Open Access in the Indonesian Higher Education Sector." Journal of the Australian Library and Information Association 66 (2): 172-73. https://doi.org/10.1080/24750158.2017.1332291.

Porter, Lyman W., and Richard M. Steers. 1973. "Organizational, Work, and Personal Factors in Employee Turnover and Absenteeism." Psychological Bulletin 80 (2): 151.

Priyanto, Ida F. 2015. "Readiness of Indonesian Academic Libraries for Open Access and Open Access Repositories Implementation: A Study on Indonesian Open Access Repositories Registered in OpenDOAR.” Ph.D., United States -- Texas: University of North Texas. http://eresources.perpusnas.go.id:2071/docview/1776621941/abstract/927153C8F8534AF 9PQ/1.

"Ranking Web of Repositories Perguruan Tinggi Keagamaan Islam Negeri (PTKIN) Sharing Is Caring." n.d. Accessed January 6, 2018. http://faizuddin.lecturer.uinmalang.ac.id/2017/02/05/ranking-web-of-repositories-perguruan-tinggikeagamaan-islam-negeri-ptkin/.

Rifaudin, Machsun. 2017. "Konsep Kepemimpinan Profetik Dalam Membangun Sumber Daya Manusia Berbasis Islam Di Perpustakaan.” JIPI (Jurnal Ilmu Perpustakaan Dan Informasi) 2 (1): 46-62.

"Robbins, P. Stephen, 2003. Perilaku Organisasi: Konsep, Kontroversi, Dan Aplikasi. Alih Bahasa Handayana Pujaatmika. Edisi Bahasa Indonesia. Jakarta: Prenhalindo. Penelusuran Google." n.d. Accessed January 6, 2018. https://www.google.com/search?q=Robbins,+P.+Stephen,+2003.+Perilaku+Organi sasi:+Konsep,+Kontroversi,+dan+Aplikasi.+Alih+Bahasa+Handayana+Pujaatmika .+Edisi+Bahasa+Indonesia.+Jakarta:+Prenhalindo.\&sa=X\&ved=0ahUKEwjecOS0sHYAhWKLo8KHd0fCzwQ6wYIKw\&biw=1366\&bih=654\&dpr=1.

Spillane, James P. 2005. "Distributed Leadership.” The Educational Forum 69 (2): 143-50. https://doi.org/10.1080/00131720508984678. 
Stueart, Robert D, and Barbara B Moran. 2007. Library and Information Center Management. 7th ed. Westport, Conn.: Libraries Unlimited. https://trove.nla.gov.au/version/31782924.

Tjiek, Liauw Toong. 2011. "Institutional Repositories: Facilitating Structure, Collaborations, Scholarly Communications, and Institutional Visibility." In Digital Libraries-Methods and Applications. InTech.

Tobing, Diana Sulianti KL. 2009. "Pengaruh Komitmen Organisasional Dan Kepuasan Kerja Terhadap Kinerja Karyawan PT. Perkebunan Nusantara III Di Sumatera Utara.” Jurnal Manajemen Dan Kewirausahaan 11 (1): pp-31. 